\title{
Ultrasound Assessment of Twin Reversed Arterial Perfusion Sequence for the Prediction of Adverse Pregnancy Outcomes in the First Trimester
}

\section{Ying Tang}

Sichuan University West China Second University Hospital

\section{Yan Zeng}

Sichuan University West China Second University Hospital

\section{Taizhu Yang}

Sichuan University West China Second University Hospital

\section{Pan Yang}

Sichuan University West China Second University Hospital

\section{Shan Bao}

Sichuan University West China Second University Hospital

\section{Hong Luo}

Sichuan University West China Second University Hospital

\section{Junjie Ying ( $\nabla$ yingjunjie177@163.com )}

Sichuan University West China Second University Hospital

\section{Research}

Keywords: early gestational age, monochorionic twin pregnancy, TRAP sequence, ultrasound, pump twin, survival

Posted Date: January 14th, 2021

DOI: https://doi.org/10.21203/rs.3.rs-142998/v1

License: (c) (1) This work is licensed under a Creative Commons Attribution 4.0 International License. Read Full License 


\section{Abstract}

Objectives

To investigate twin reversed arterial perfusion (TRAP) sequence for the prediction of TRAP-related adverse pregnancy outcomes at the gestational age of 11-14 weeks.

Methods

Pregnant women in the first trimester diagnosed with TRAP were recruited at West China Second University Hospital from January 2015 to June 2018. Systematic screening for the pump twin's crownrump length $(C R L)$ and acardiac twin's upper pole-rump length $(U R L)$ was conducted using ultrasonic detection. The (CRL-URL)/CRL and URL/CRL ratios were used to assess the pregnancy outcomes for the pump twin.

Results

Twenty-one pregnant women aged 21-39 years with a gestation of 11-14 weeks were recruited. TRAP was diagnosed on average ( \pm standard deviation [SD]) at pregnancy week $13.1 \pm 0.18$. The pump twins' mean $( \pm$ SD) $C R L$ was $6.65 \pm 1.1 \mathrm{~cm}$. The incidence of intrauterine death for the pump twins was $19.0 \%$ $(n=4)$, the miscarriage rate was $14.3 \%(n=3)$, and the live birth rate was $66.7 \%(n=14)$. The (CRL-URL)/CRL ratios between the non-survival (intrauterine death and miscarriage) and survival groups significantly differed $(0.33 \pm 0.08$ vs. $0.58 \pm 0.08, p<0.05)$. Similarly, the URL/CRL ratios between the non-survival and survival groups significantly differed $(0.67 \pm 0.08$ vs. $0.42 \pm 0.08, p<0.05)$.

Conclusions

The (CRL-URL)/CRL and URL/CRL ratios were valuable indicators for determining pregnancy outcomes of pump twins with TRAP at an early gestational age.

\section{Background}

Twin reversed arterial perfusion (TRAP) sequence is a severe complication of monochorionic twin pregnancy, accounting for $1 \%$ of all complications [1]. TRAP is usually caused by an abnormal vascular anastomosis leading to a non-equilibrium arterial pressure between the twins. The pump twin with a higher arterial pressure will cause retrograde perfusion of the blood to the acardiac twin. The malformation of the acardiac twin is characterized by the absence of cardiac structure. The survival of the acardiac twin depends on the blood provided by the pump twin. Most of the acardiac twins die after birth. The acardiac twin severely influences the intrauterine development of the pump twin. Studies have shown that approximately $60 \%$ of pump twins can develop heart failure, intrauterine death, miscarriage, and premature birth due to the acardiac twin presence $[1,2]$. 
Ultrasound examination is the first-line method to diagnose and monitor TRAP. One study demonstrated that larger acardiac twins were associated with a higher incidence of adverse pregnancy outcomes (30\%, $40 \%$, and $90 \%$ for heart failure, edema, and premature delivery and miscarriage, respectively) [2]. As recommended in the World Health Organization guidelines on the tertiary prevention of birth defects, researchers and medical practitioners globally are committed to the early detection of TRAP. Therefore, it is important to identify the ultrasound indicators for the prediction of adverse pregnancy outcomes of pump twins with TRAP at 11-14 weeks of gestation. This will assist in devising a reasonable pregnancy management strategy to promote the survival of pump twins. Some studies reported that ultrasound indicators such as pump twin's crown-rump length (CRL) and acardiac twin's upper pole-rump length (URL) in early pregnancy were accurate in indicating the outcomes for the twins. The (CRL-URL)/CRL and URL/CRL ratios were significantly associated with adverse pregnancy outcomes of the pump twins $[1,3]$. However, there are no accepted criteria to predict adverse pregnancy outcomes of pump twins.

We conducted a study which aimed to explore the ultrasound indicators for the prediction of outcomes for the pump twin with TRAP at a gestational age of 11-14 weeks.

\section{Methods}

\section{Study participants}

We performed a study of pregnant women affected by TRAP sequence in West China Second University Hospital, Sichuan University from January 2015 to June 2018. Participants with a gestation of 11-14 weeks were diagnosed using the first-trimester fetal ultrasound. The exclusion criteria included the following: (1) complications of severe multi-organ disorders or a genetic family history, (2) triplet pregnancy, (3) inability to complete follow-up for various reasons, (4) death of the twins prior to the examination, and (5) induction before a gestation of 16 weeks. Ethical approval for this study was obtained from the West China Second University Hospital Research Ethics Board (JS-833). Informed consent was signed by the examined pregnant women.

\section{Ultrasound examination}

Voluson 730, Voluson E8, and iU22 color Doppler flow imaging (GE and Philips) were used for transabdominal ultrasound examination. If necessary, a combination of transvaginal and ultrasound examination was performed. TRAP sequence was identified as twins with one anatomically normal retrograde perfusion and the other without functional cardiac activity in a monochorionic twin pregnancy. Monochorionic diamniotic (MCDA) is defined as a very thin membrane between the twins and absence of " $\lambda$ " sign via ultrasound detection in the monochorionic twin pregnancy. Monochorionic monoamniotic (MCMA) is defined as absence of membrane echo between the twins.

The following data from ultrasound examination were collected: $C R L$ of the twins, URL of the twins, nuchal translucency (NT) thickness, ductus venosus (DV) blood flow spectrum, birth weight of the pump 
twin. An abnormal NT thickness was defined as NT $\geq 3 \mathrm{~mm}$. An abnormal DV was defined as an inverted or disappearance of the a-wave in the pump twin.

We performed a routine systemic ultrasound screening of the pump twin, and observed whether there were abnormal anatomical structures in the organs of the pump twin. We assessed the development of the twins, as well as the placenta and amniotic fluid of the twins. We observed the vessels, umbilical cord, and the umbilical artery blood flow. Additionally, we assessed whether there was an overlap of the twins' umbilical cords at the placental attachment site and the site of umbilical cord insertion into the placenta. Finally, we evaluated whether there was cord entanglement in the MCMA twins.

\section{Other examinations, clinical management, and follow-up}

Fetal specialists conducted assessments and monitored the development of the twins. The specialist had consultations with the patients regarding their existing diseases, and informed the patients of the risks of the acardiac twin to the pump twin in the uterus. The specialists also explained the advantages and limitations of expectant management and invasive intrauterine treatment. Expectant management was when the specialists monitored the growth rate of the acardiac twins, the growth status of the pump twins, the blood flow states (e.g. umbilical artery, DV and middle cerebral artery), and heart functions of the pump twins using ultrasound examinations each week. Invasive intrauterine treatment was performed by the specialists. They used bipolar electrocoagulation to cease blood supply to the acardiac twin, maintaining the growth of the pump twin. If they found a thick NT in the twin, they would recommend a fetal chromosome examination after taking into account the risk factors, such as high maternal age. Both the specialist and the patient made the final clinical decision, provided the decision conformed to current laws and ethics. A research group consisting of physicians from the obstetrics department, the pediatrics department, and the ultrasonography department followed up on the outcome of the pregnancy by telephone and face-to-face conversations, and inpatient records. The primary outcome was live birth, intrauterine fetal death, and miscarriage. Participants were separated into non-survival (intrauterine death and miscarriage) and survival (live birth) groups based on their primary outcome.

\section{Statistical analysis methods}

We analyzed relevant indices using the Man-Whitney-U test and a multiple logistic regression Variable data was given as median (interquartile range [IQR]). SPSS 16.0 and STATA were used for analysis of the data. P-values $<0.05$ were considered statistically significant.

\section{Results}

We prospectively recruited a total of 31 pregnant women diagnosed with TRAP from January 2015 to June 2018. The patients were 21-39 years of age; the twins' average ( \pm standard deviation [SD]) gestational age was $13.1 \pm 0.18$ weeks when TRAP was diagnosed. The mean $( \pm S D) C R L$ of the pump twin was $6.65 \pm 1.10 \mathrm{~cm}$. Of the 31 pregnant women, 29 women were naturally pregnant, while the remaining two women were pregnant as a result of artificial insemination using the test tube method. There were two cases of triplet pregnancy and eight cases of induced abortion (one case of induced 
abortion was caused by the pump twin's malformations, one case was caused by the pump twin's abnormal chromosomes, and six cases were caused by psychosocial factors) who were excluded. The remaining 21 patients ( $n=3$ MCMA twins and $n=18$ MCDA twins) were finally included.

The outcomes of the pump twin are shown in Table 1. The intrauterine death rate of pump twins was $19.0 \%(n=4)$, the abortion rate was $14.3 \%(n=3)$, and the live birth rate was $66.7 \%(n=14)$. The premature birth rate before 34 weeks' of gestation was $28.6 \%(n=6)$. Among the 21 pump twins, two pump twins were birthed. However, their family abandoned the treatment. Overall, $57.2 \%(n=12)$ of twins were involved in the follow-up with a good development. 
Table 1

TRAP clinical records and pump twin' perinatal outcomes

\begin{tabular}{|c|c|c|c|c|c|}
\hline \multirow[t]{2}{*}{ Case } & \multirow[t]{2}{*}{ Chorionicity } & \multirow[t]{2}{*}{ Management } & \multirow{2}{*}{$\begin{array}{l}\text { GA at delivery week } \\
\text { and way of delivery }\end{array}$} & \multicolumn{2}{|c|}{ Pump twin } \\
\hline & & & & $\begin{array}{l}\text { Birth } \\
\text { weight } \\
\text { (g) }\end{array}$ & Outcome \\
\hline 1 & MCDA & $\begin{array}{l}\text { Bipolar electrocoagulation } \\
\text { during expectant } \\
\text { management }\end{array}$ & $25^{+3} \mathrm{WVD}$ & 220 & IFD \\
\hline 2 & MCDA & $\begin{array}{l}\text { Bipolar electrocoagulation } \\
\text { during expectant } \\
\text { management }\end{array}$ & 24 w VD (PROM) & 168 & Miscarriage \\
\hline 3 & MCDA & $\begin{array}{l}\text { Bipolar electrocoagulation } \\
\text { during expectant } \\
\text { management }\end{array}$ & $32^{+4} w$ VD & 1643 & Good \\
\hline 4 & MCDA & $\begin{array}{l}\text { Bipolar electrocoagulation } \\
\text { during expectant } \\
\text { management }\end{array}$ & $38^{+3} \mathrm{w} C S$ & 3240 & Good \\
\hline 5 & MCDA & $\begin{array}{l}\text { Bipolar electrocoagulation } \\
\text { during expectant } \\
\text { management }\end{array}$ & 35 w VD & 2785 & Good \\
\hline 6 & MCDA & $\begin{array}{l}\text { Bipolar electrocoagulation } \\
\text { during expectant } \\
\text { management }\end{array}$ & $33^{+4}$ w CS & 1870 & Good \\
\hline 7 & MCDA & Expectant management & $36^{+5}$ w CS & 2990 & Good \\
\hline 8 & MCMA & Expectant management & $31^{+4} \mathrm{w}$ VD & 1363 & IFD \\
\hline 9 & MCDA & Expectant management & $35^{+3} \mathrm{w} \mathrm{CS}$ & 2340 & Good \\
\hline 10 & MCMA & Expectant management & 18 w VD & 185 & IFD \\
\hline 11 & MCDA & Expectant management & 19 w VD & 121 & Miscarriage \\
\hline 12 & MCDA & Expectant management & $29^{+4} w$ VD & 1510 & $\begin{array}{l}\text { Abandoning } \\
\text { treatment }\end{array}$ \\
\hline 13 & MCDA & Expectant management & $37 w$ VD & 3378 & Good \\
\hline 14 & MCMA & Expectant management & $31^{+6} \mathrm{w}$ VD & 1862 & Good \\
\hline 15 & MCDA & Expectant management & $32^{+5} \mathrm{w}$ VD & 1785 & $\begin{array}{l}\text { Abandoning } \\
\text { treatment }\end{array}$ \\
\hline 16 & MCDA & Expectant management & 36 w CS & 2569 & Good \\
\hline 17 & MCDA & Expectant management & 22 w VD & 196 & IFD \\
\hline
\end{tabular}




\begin{tabular}{|c|c|c|c|c|c|}
\hline \multirow[t]{2}{*}{ Case } & \multirow[t]{2}{*}{ Chorionicity } & \multirow[t]{2}{*}{ Management } & \multirow{2}{*}{$\begin{array}{l}\text { GA at delivery week } \\
\text { and way of delivery }\end{array}$} & \multicolumn{2}{|c|}{ Pump twin } \\
\hline & & & & $\begin{array}{l}\text { Birth } \\
\text { weight } \\
\text { (g) }\end{array}$ & Outcome \\
\hline 18 & MCDA & Expectant management & $37^{+2}$ w CS & 3361 & Good \\
\hline 19 & MCDA & Expectant management & $36^{+1}$ w CS & 2907 & Good \\
\hline 20 & MCDA & Expectant management & $24^{+3} w$ VD & 165 & Miscarriage \\
\hline 21 & MCDA & Expectant management & 39 w CS & 4120 & Good \\
\hline \multicolumn{6}{|c|}{$\begin{array}{l}\text { Abbreviation: CS, cesarean section; GA, gestational age; IFD, intrauterine fetal death; MCDA, } \\
\text { monochorionic diamniotic; MCMA, monochorionic monoamniotic; PROM, premature rupture of the } \\
\text { membranes; TRAP, twin reversed arterial perfusion sequence; VD, vaginal delivery. }\end{array}$} \\
\hline
\end{tabular}

We performed expectant management in 21 cases. Six cases of expectant management showed significant growth of the acardiac twins during the gestational ages of 24-26 weeks accompanied with polyhydramnion of the pump twins. They were subjected to bipolar electrocoagulation in the umbilical cords of the acardiac twins. Among the six cases, one pump twin died of heart failure and polyhydramnion in utero 2 days after the surgery. One case had an abortion at a gestational age of 24 weeks. Two cases showed premature rupture of membranes (PROM) within 3 days after the surgery. One case was born vaginally at 33 weeks with prevention measures enacted to prevent miscarriage from the gestational age of 25 weeks. In five (23.8\%) cases, the blood flow of the acardiac twins was naturally blocked. Among these cases, four pump twins survived and one pump twin died of heart failure at the gestational age of 21 weeks; this was 1 week after the natural blood flow obstruction to the twin. In two cases diagnosed with MCMA, the patients had polyhydramnion at the gestational ages of 18 and 31 weeks. The two pump twins died of heart failure in utero. The cord entanglement was observed after induced abortion. In two cases, the polyhydramnion caused abortions at the gestational ages of 19 and 24 weeks. Four pump twins survived ( $n=1$ and $n=3$ MCMA and MCDA twins, respectively). Two families with pump twins abandoned the treatment.

There were significant differences in the $(C R L-U R L) / C R L(0.33 \pm 0.08$ vs. $0.58 \pm 0.08, p<0.05)$ and URL/CRL $(0.67 \pm 0.08$ vs. $0.42 \pm 0.08, p<0.05)$ ratios between the pump twin in the non-survival and survival groups. A (CRL - URL)/CRL ratio $>0.43$ or a URL/CRL ratio $<0.57$ identified the pump twin survivors. Multiple regression analysis showed that the (CRL-URL)/CRL and URL/CRL ratios were significantly associated with the survival of the pump twins after controlling for the other variables $(p<$ 0.05) (Table 2, Fig. 1). 
Table 2

Ultrasound indicators of TRAP in the first trimester according to pregnancy outcome

\begin{tabular}{|c|c|c|c|}
\hline Characteristic & $\begin{array}{l}\text { Pump twin with adverse outcome (n } \\
=7 \text { ) }\end{array}$ & $\begin{array}{l}\text { Survival pump twin }(n= \\
\text { 14) }\end{array}$ & $\mathbf{P}$ \\
\hline CRL (mm) & $6.58 \pm 0.94$ & $6.80 \pm 1.10$ & $\begin{array}{l}P= \\
0.16\end{array}$ \\
\hline URL (mm) & $4.40 \pm 0.92$ & $2.85 \pm 0.07$ & $\begin{array}{l}P= \\
0.02\end{array}$ \\
\hline $\begin{array}{l}\text { Ratio of (CRL- } \\
\text { URL)/CRL }\end{array}$ & $0.33 \pm 0.08$ & $0.58 \pm 0.08$ & $\begin{array}{l}\mathrm{p}< \\
0.05\end{array}$ \\
\hline Ratio of URL/CRL & $0.67 \pm 0.15$ & $0.42 \pm 0.10$ & $\begin{array}{l}\mathrm{p}< \\
0.05\end{array}$ \\
\hline \multicolumn{4}{|c|}{$\begin{array}{l}\text { Abbreviation: CRL, crown-rump length; DV, ductus venosus; NT, nuchal translucency; TRAP, twin } \\
\text { reversed arterial perfusion sequence; URL, upper pole-rump length. }\end{array}$} \\
\hline \multicolumn{4}{|c|}{ Adverse outcome of pump twin included intrauterine death and miscarriage. } \\
\hline
\end{tabular}

\section{Discussion}

We found that the (CRL-URL)/CRL and URL/CRL ratios significantly differed between the survival and non-survival groups at 11-14 weeks of gestation. These results were consistent with the findings from Roethlisberger et al. in which the (CRL-URL)/CRL and URL/CRL ratios were potential predictors of TRAP pregnancy outcomes during early gestational ages [1].

Several studies have shown that the size of the acardiac twin was associated with the outcomes of the pump twin $[2,4,5]$. Moore et al. summarized the clinical outcomes of 49 cases of TRAP [2]. When the ratio of the acardiac twin body weight to the pump twin body weight was more than $70 \%$, the risk of an adverse outcome for the pump twin increased. Jelin et al. analyzed 18 acardiac twins whose body weights were no more than $50 \%$ of those of the pump twins; they found that only one pump tiwn with MCMA twins died in utero [4]. One study conducted in the Children's Hospital of Philadelphia, investigating 13 cases of TRAP, found that when the body weights of the acardiac twins were no more than $40 \%$ of those of the pump twins, no edema and heart failure were seen in the pump twins [5]. These findings were consistent with our findings. In the first trimester, it is easy to conduct the measurement of the fetal length using an ultrasound. Additionally, it can provide potential predictors to guide the clinical management of TRAP during early gestational ages.

The treatment of TRAP aims to increase the pump twin's survival rate. The key treatment method is to block the blood flow of the acardiac twin and allow the pump twin to recover from the abnormal circulation. Snijders et al. found that TRAP can be diagnosed at 11-14 weeks of gestation, supporting the need for the early clinical management of TRAP [6]. However, there is no consistent management for TRAP. Some specialists prefer to perform expectant management $[4,5]$. Several studies have indicated that the intrauterine mortality rate of the pump twins after expectant management ranged from 43 to 
$100 \%[1,3]$. The timely use of micro-invasive therapy in utero such as radiofrequency ablation and bipolar cord coagulation can increase the survival rate of the pump twin to some extent. The International Society of Ultrasound in Obstetrics and Gynecology demonstrated that it was feasible to perform microinvasive preventive surgery on cases with TRAP before 16 weeks of gestation [7]. However, some specialists are concerned that intrauterine therapy for the fetus with a gestational age of 16 weeks may cause the PROM, maternal pulmonary edema, placental damage, and that it may also increase the risk of skin damage and neural damage of the pump twin, as well as the death rate of the pump twin $[1,8,9]$. Therefore, it is pivotal to establish reasonable management strategies for TRAP.

Various studies suggested that expectant management may be a good management strategy for TRAP. One study conducted in Australia found that the survival rate of the pump twin was more than $80 \%$ after the expectant management of TRAP [10]. In our study, 21 cases received expectant management and the survival rate of the pump twin was $66.7 \%$.

Some studies suggested that an invasive intrauterine intervention may be conducted in the pump twin if discovered that there is polyhydramnion, the abdominal circumference of the acardiac twin is equal to or greater than that of the pump twin, or the pump twin has severe abnormal blood flow $[4,11,12]$. Severe abnormal blood flow was defined as blood flow in the umbilical artery reversed or disappeared at the diastolic phase, pulsatory blood flow of the umbilical vein or DV in the reverse direction, a peak systolic velocity of the middle cerebral artery $>1.5 \mathrm{MOM}$, or a pulse index of DV $>95 \%$. In our study, when edema, heart failure, and polyhydramnion in the pump twin occurred or the body weight of the acardiac twin was greater than $50 \%$ of that of the pump twin, it was recommended that invasive management be performed. Among the 21 cases, six cases were subjected to bipolar electrocoagulation in the umbilical cords of the acardiac twins at $24-26$ weeks of gestation. Overall, $66.7 \%(n=14)$ of the pump twins experienced a live birth.

In some TRAP cases, the blood flow of the acardiac twins may be naturally blocked in development. Chen et al. reported that there were seven cases of naturally blocked TRAP, with three cases of intrauterine death and one case of polyhydramnion-induced premature birth [13]. In our study, we identified five TRAP cases with naturally blocked blood flow, of which four cases survived. In one case, the pump twin had polyhydramnion within 1 week after the natural blocking of the blood flow. The pressure in the umbilical blood vessels abruptly decreased after the natural blocking of the blood flow of the acardiac twin. The blood flow of the pump twin was perfused to the acardiac twin, thereby increasing the cardiac burden on the pump twin. The pump twin consequently developed heart failure with a high cardiac output, and thereafter died of heart failure. Therefore, ultrasounds can be used in TRAP cases to monitor the development of the pump twin after the natural blood flow has been blocked.

Some studies have indicated that the resistance index of the umbilical artery and the pulsatility index of the middle cerebral artery may be indicators to assess the prognosis of TRAP [14, 15]. However, these indicators for blood flow in TRAP were detected at gestational ages of greater than 20 weeks; thus, some important indicators may have eluded observation in the first trimester. Therefore, high-quality studies are 
required in the future to explore the ability of ultrasounds to predict adverse outcomes of TRAP in the first trimester.

\section{Conclusion}

In conclusion, the (CRL-URL)/CRL and URL/CRL ratios were effective indicators for predicting adverse pregnancy outcomes for the pump twins with TRAP at 11-14 weeks of gestation in this study. After invasive management or the natural blood flow is blocked during expectant management, the pump twin with TRAP should be monitored using ultrasound.

\section{Declarations}

\section{Statement of Ethics}

Ethical approval for this study was provided by the West China Second University Hospital Research Ethics Board (JS-833).

\section{Acknowledgments}

Not applicable.

\section{Author Contributions}

Ying Tang, Junjie Ying, and Hong Luo conceptualized the study, designed the study, drafted the initial manuscript, and revised the manuscript. Pan Yang, Shan Bao followed up the patients and conducted the expectant management. Ying Tang, Yan Zeng and Pan Yang collected data and conducted the initial analyses. Taizhu Yang and Junjie Ying critically reviewed the manuscript. All authors approved the final manuscript as submitted and agree to be accountable for all aspects of the work.

\section{Funding}

This work was supported by the Technology Innovation Research and Development Project of Chengdu Bureau of Science and Technology (2019-YF05-00185-SN) and Applied and Basic Research Project of Sichuan Province (21YYJC2454).

\section{Conflict of Interest Statement}

The authors have no conflicts of interest to declare.

\section{References}

1. Roethlisberger M, Strizek B, Gottschalk I, et al. First trimester intervention in twin reversed arterial perfusion (TRAP) sequence - does size matter? Ultrasound in Obstetrics \& Gynecology 2017; 50:4044. 
2. Moore TR, Gale S, Benirschke K. Perinatal outcome of forty-nine pregnancies complicated by acardiac twinning. Am J Obstet Gynecol 1990; 163:907-12.

3. Lewi L, Valencia C, Gonzalez E, et al. The outcome of twin reversed arterial perfusion sequence diagnosed in the first trimester. Am J Obstet Gynecol 2010; 203:213.e1-.e4.

4. Jeline, Hirose $S$, Rand $L$, et al. perinatal outcome of conservative management versus fetal intervention for twin reversed arterial perfusion sequence with a small acardiac twin. Fetal Diagn Ther 2010; 27:138-141.

5. Mann S, Johnson MP, Rosner M, Wilson RD, Bebbington M. Prognostic indicators in twin reversed arterial perfusion sequence: Does size matter? Supplement to December 2007 Am J Obstet Gynecol. s147.

6. Snijders RJ, Noble P, Sebire N, Souka A, Nicolaides KH. UK multicentre project on assessment of risk of trisomy 21 by maternal age and fetal nuchal-translucency thickness at 10-14 weeks of gestation. Fetal Medicine Foundation First Trimester Screening Group. Lancet 1998; 352:343-346.

7. Khalil A, Rodgers M, Baschat A, et al. ISUOG practice guidelines: the role of ultrasound in twin pregnancy. Ultrasound Obstet Gynecol 2016; 47:247-263.

8. Lee $\mathrm{H}$, Bebbington $\mathrm{M}$, Crombleholme TM. The north American Fetal Therapy network registry dataonoutcomes of radiofrequency ablation for twin reversed arterial perfusion sequence. Fetal Diagn Ther 2013; 33:224-229.

9. Berg C, Holst D, Mallmann MR, et al. Early vslate intervention in twin reversed arterial perfusion sequence. Ultrasound Obstet Gynecol 2014; 43:60-64.

10. Fisher KE, Welsh A W , Henry A. Uncommon complications of monochorionic twin pregnancies: Twin reversed arterial perfusion sequence. Australasian Journal of Ultrasound in Medicine 2016; 19:133-141.

11. Quintero RA, Chmait RH, Murakoshi T, et al. Surgical management of twin reversed-arterial perfusion sequence. Am J Obstet Gynecol 2006; 194:982-991.

12. Weisz B, Peltz R, Chayen B, et al. Tailored management of twin reversed-arterial perfusion sequence (TRAP). Ultrasound Obstetric Gynecol 2004; 23:451-455.

13. X. Chen, X. Yang. Ultrasound imaging of acardia blood spontaneously blocked before and after and pump twin outcome in twin reversed arterial perfusion sequence. Ultrasound Obstet Gynecol 2014; 44:181-369.

14. Chen Chang-yu, Xie Li-mei. Clinical value of difference in umbilical artery blood flow resistive index between pump and acardiac twins in predicting outcome of pump twin by twin reversed-arterial perfusion sequence. BME $\triangle$ Clin Med 2016; 20:149-153.

15. Peyvandi S, Feldstein V.A, Hirose $S$, et al. Twin-reversed arterial perfusion sequence associated with decreased fetal cerebral vascular impedance. Ultrasound Obstet Gynecol 2015; 45: 447-451.

\section{Figures}




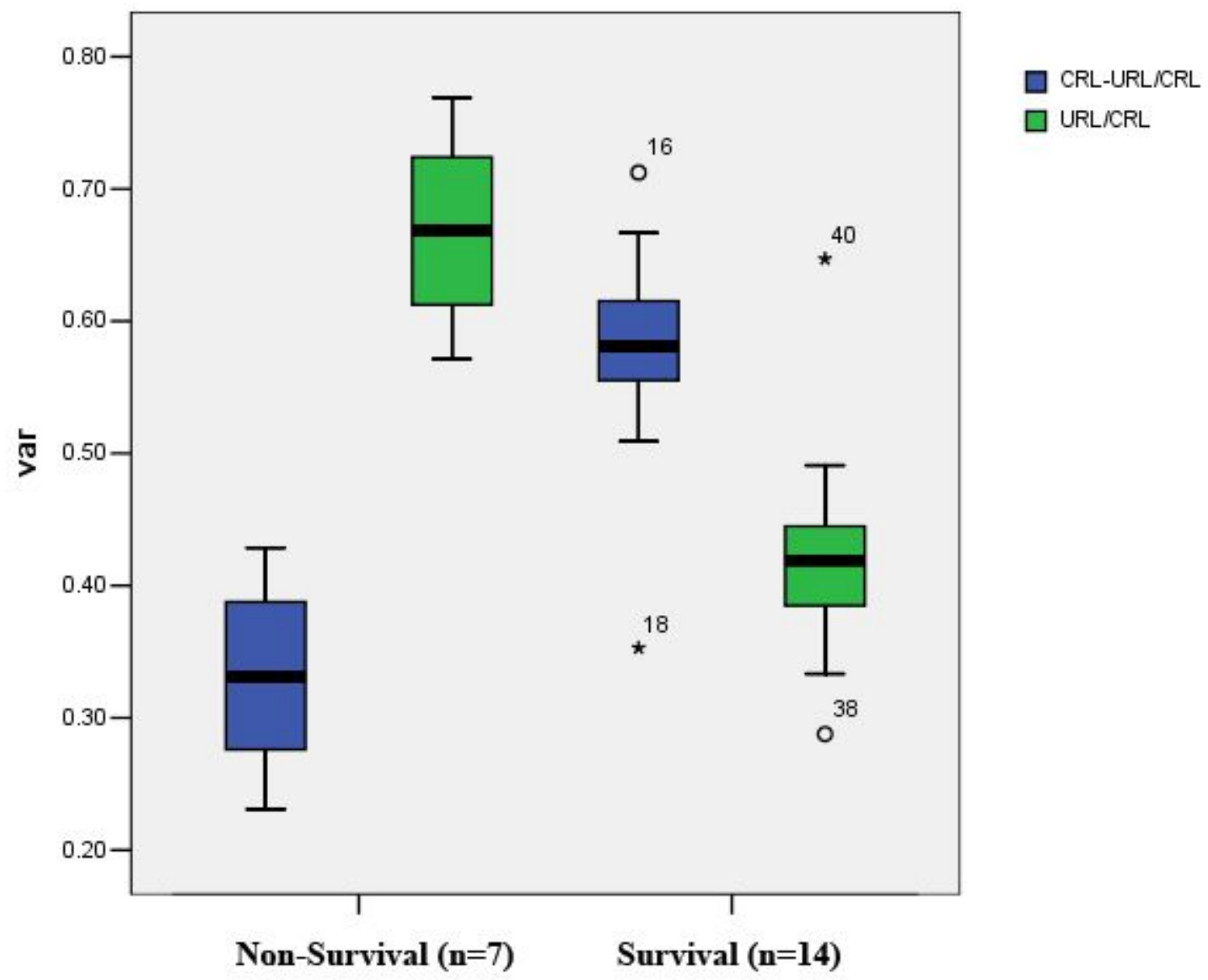

Figure 1

(CRL-URL)/CRL and URL/CRL in the pump fetus survival group and non-survival group. Boxes present median and upper and lower quartiles and whiskers present range. Crown-rump length, CRL; upper polerump length, URL. 